\title{
Overhauling health care Down Under
}

$\mathrm{F}$ ew developed nations in recent history have sought such systemic reform to its health care system as Australia, which over the course of the past four years has squabbled over jurisdictional issues, funding, primary care reform and a host of other issues in a bid to implement its most significant overhaul of health care since universality was introduced in 1975 .

The overhaul culminated with the signing of the National Health Reform Agreement in August 2011 between the Commonwealth and eight state or territorial governments (www.coag.gov.au /docs/national_health_reform_agreement .pdf). But already critics are saying the reforms were inadequate and may well be doomed to ultimately become mired in the same jurisdictional quagmires that have long plagued Australian health care.

The agreement features a host of new financial and governance arrangements for public hospital services, including more activity-based funding of hospitals and a significant $\mathrm{A} \$ 20$ billion boost in funding for public hospitals over the next decade. It also makes the federal government fully responsible for funding and delivering "aged care"; introduces a plan to reduce emergency department and elective surgery wait times; and creates several independent oversight bodies, such as the Australian Commission on Safety and Quality in Health Care to improve standards of clinical care and the Independent Hospital Pricing Authority to help improve primary care delivery.

But the final agreement fell short on one of the key objectives identified at the start of the exercise - a blending of federal and state government services and funding that health experts say would have substantially improved access to medical services and streamlined health care delivery.

"A lot of our problems stem from the federal-state divide and the fact that primary care sits with one government and secondary care sits with another eight governments," says Philip Davies, pro-

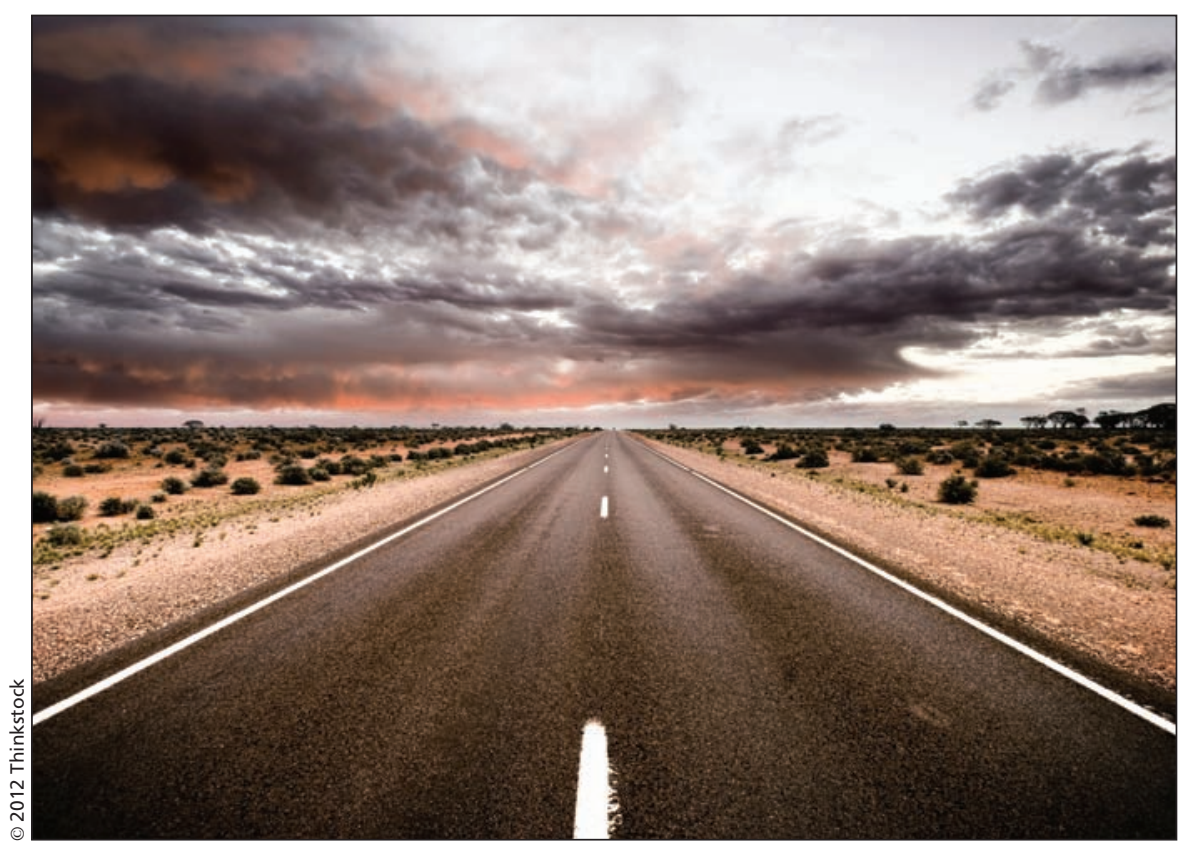

Among the major challenges faced by the Australian health system is delivering care in remote and indigenous communities where care is often scant.

fessor of health systems and policy at the University of Queensland's School of Population Health in Brisbane, Australia. "In an environment where most health systems are trying to migrate services across that primary-secondary boundary for reasons of effectiveness and efficiency, we've got that boundary rigorously built into our structure."

Australia's constitution makes the federal government responsible for national health policy, subsidization of public hospitals and funding of medical services and pharmaceuticals under medicare. State and territorial governments are responsible for public health services, such as dental, maternal and child health care; all direct care, including most acute and psychiatric hospital services; as well as a portion of the funding of public hospitals. The reforms will tie federal funding to the number of services performed at hospitals, which proponents hope will introduce a measure of accountability into the system.

The drive to reform the system was aimed at improving health outcomes at a time when Australia faces explosive growth in health care costs, an aging population, a higher incidence of chronic diseases and growing demand for services, particularly in remote and indigenous communities where care is often scant.

The system now costs roughly A $\$ 120$ billion per year. Costs have been rising at about a $9 \%$ rate for the past five years, while the revenues of state and territorial government have grown by about $6 \%$ annually.

The agreement essentially trades an increase in federal funding in exchange for reforms to be undertaken by the states. "In recognition of the implementation by the States of these reforms, the Commonwealth will provide at least an additional $\$ 16.4$ billion in growth funding between [fiscal] 201415 and 2019-20 through meeting 45 per cent of efficient growth between 201415 and 2016-17 and 50 per cent of efficient growth from 2017/18 onwards; in the event the additional growth funding is less than $\$ 16.4$ billion, the Commonwealth will provide the remainder to States as top-up funding." 
But not all observers are convinced that the financing arrangements have gone far enough. "Australia's health spend is now more than $[\mathrm{A}] \$ 120$ billion each year, and the inefficiencies that come with cost-shifting between federal and state/territory governments mean we continue to put greater importance on hospital beds over integrated primary care," says Carol Bennett, CEO of the Consumers Health Forum.

Others are calling it a step in the right direction. "One of the underlying objectives of the government is to make primary health care more central to the health care system than it is now, and as a long-term objective to put more value in health promotion and prevention and keeping people out of hospital," says Dr. David Briggs, coordinator of health management and gerontology programs at the University of New England's School of Health in Armidale, Australia.

Bennett lauds the changes to activity-based funding of public hospitals, which will see facilities paid according to the number and type of services they deliver. "While the national health reforms weren't able to deliver a single funder for the health system, they did establish the national pricing and performance authorities," she says. "This move to activity-based funding across all Australia's public hospitals should ensure greater accountability and efficiency for delivery of care within the acute system."

Under the agreement, the federal government will fund $45 \%$ of "efficient growth of activity based services [in public hospitals], increasing to 50 per cent from 1 July 2017. Efficient growth consists of: a) the national efficient price for any changes in the volume of services provided ... and $b$ ) the growth in the national efficient price of providing the existing volume of services." The "national efficient price" will be determined by the Independent Hospital Pricing Authority.

Davies notes that hospitals currently "suffer from a lot of the malaise that you see in large, publicly owned and publicly operated institutions, a certain inability to adopt new ways of working, not a strong focus on driving efficiency. ... This focus on patient services and activity-based funding may well assist in changing the hospitals and improving patient care."

The reforms also set out emergency department and elective surgery targets. In the former instance, to be phased in over four years, the goal is to have $90 \%$ of patients admitted, referred or discharged within four hours. In the latter case, the goal is to have all procedures completed within specified times to be established by a National Health Performance Authority. Smaller regions, such as Tasmania, the Australian Capital Territory and the Northern Territory, will be given until 2016 to meet the targets.

Davies foresees problems. "If you increase capacity, you increase demand. You're sort of chasing your tail with these kinds of initiatives. If you know you're only going to have to wait half an hour instead of two hours in the emergency department, you're more likely to go there. And a doctor will be more likely to refer a patient for a marginal elective surgery if the waiting times reduce."

The agreement also proposes new governance mechanisms for primary care, in the form of "local health networks" to oversee delivery of public hospital services and "medicare locals" to coordinate primary care delivery and ensure that community needs, such as after-hours care, are met.

"Previously there was no overarching framework for primary health care. These organizations are about to deliver that," says Briggs, who will chair a medicare local. "The hope is the medicare locals and local health networks will work with their local communities, populations and health professionals to identify health needs and gaps in primary health care, and then fill those gaps and provide better integrated care and continuity of care."

The agreement also provides $\mathrm{A} \$ 1.6$ billion to expand the number of inpatient sub-acute (for example, rehabilitative and palliative) care beds in hospitals, as well as $\mathrm{A} \$ 2.2$ billion over five years to improve mental health services.

Among other significant provisions is federal government responsibility for basic community care for all people over age 65 in all states and territories except Western Australia and Victoria. To that end, the federal government indicated it will increase capacity by adding 5000 spaces and 1200 "packages of care" (essentially services such as registered nursing care and transportation to appointments, to assist seniors to live in their own homes) by 2013.

"There will undoubtedly be some benefits" that accrue from the reforms, Davies says. "But the question you have to ask is: Are they benefits that could have been achieved more easily and more quickly without the whole circus of reform. If we'd actually spent the last four years doing things rather than designing things we may well have made as much progress." Tanalee Smith, Adelaide, Australia

CMAJ 2012. DOI:10.1503/cmaj.109-4099 